\title{
A REVIEW ON NANOEMULSIONS: FORMULATION, COMPOSITION, AND APPLICATIONS
}

\author{
KHAN MOHAMMAD HAMID*, MOHAMMAD WAIS, GAURANG SAWANT
}

Department of Pharmaceutics, H.K. College of Pharmacy, Oshiwara, Mumbai, India. Email: mondhamid181@gmail.com

\author{
Received: 22 January 2021, Revised and Accepted: 09 March 2021
}

\begin{abstract}
Nanoemulsions are sub-micron sized emulsions that are undergoing detailed assessment as potential drug carriers for enhancing the delivery of therapeutic agents. These are to date the most developed nanoparticulate systems for the systemic delivery of active pharmaceutical for controlled drug delivery as well as targeting. These are the thermodynamically durable isotropic system, in which two incompatible liquids (water and oil) are blended to form a single homogenous phase by utilizing a required quantity of surfactants to achieve mixing with a droplet diameter approaching roughly in the range of $0.5-100 \mu \mathrm{m}$. They find applications in various fields such as cosmetics as well as are adopted in various routes of administration.
\end{abstract}

Keywords: Nanoemulsion, Nanoparticle, Droplet size, Cosmetics.

(C) 2021 The Authors. Published by Innovare Academic Sciences Pvt Ltd. This is an open access article under the CC BY license (http://creativecommons.org/ licenses/by/4.0/) DOI: http://dx.doi.org/10.22159/ajpcr.2021v14i4.40859. Journal homepage: https://innovareacademics.in/journals/index.php/ajpcr

\section{INTRODUCTION}

Nanoemulsions (NEs) are known as oil-in-water (o/w) emulsions with average droplet sizes falling from 50 to $1000 \mathrm{~nm}$. Normally, the mean droplet size is between 100 and $500 \mathrm{~nm}$, for which terminologies such as sub-micron emulsion (SME) and mini-emulsion are adopted instead. The NEs play the role as a base for manufacturing polymer latex particles, nonporous polymeric solids, etc. In addition, the NEs with pharmaceutically established excipients are used in the manufacturing of drug formulations for oral drug delivery. The NEs are also called by other names such as mini emulsions, ultrafine emulsions as well as SMEs. Phase behavior studies have demonstrated that the dimensions of the droplets are decided by the surfactant phase structure (bicontinuous microemulsion or lamellar) at the inversion point brought about by either temperature or composition. Investigations on NE formation by employing the phase inversion temperature method have conveyed a relationship between minimum droplet size and full solubilization of the oil in a microemulsion bicontinuous phase irrespective of even if the primitive phase equilibrium exists in single or multiphase. Due to their small droplet size, NEs provide stability against sedimentation or creaming with Ostwald ripening being the pivotal pathway of NE degradation. The principal application of NEs in the formulation of nanoparticles by employing a polymerizable monomer serving as the disperse phase (the so-called miniemulsion polymerization method) where NE droplets function as nanoreactors. Another fascinating application is formulating NEs containing active pharmaceutical ingredients (APIs), namely, for controlled drug delivery as well as targeting [1].

\section{Formulation of microemulsions}

Many different methods have been utilized for the formulation of NEs examples being high-pressure homogenization, microfluidization, phase inversion, spontaneous emulsification, solvent evaporation as well as hydrogel formation each having unique process [2-5]. Multiple emulsions are normally prepared by utilizing the double emulsion solvent evaporation method. NEs are prepared chiefly using two key methods, (a) the persuasion method and (b) the Brute force method.

\section{Persuasion methods/phase inversion techniques}

$\mathrm{NE}$ formulation by persuasion method proceeds in the absence of external force, but as a substitute, it requires the emergence of fine dispersions when phase transitions occur by swapping either the temperature or composition while maintaining the other parameter constant. The persuasion method can be widely categorized into, (i) phase transition from the near-optimum state through a change in a single variable, which involves changing one variable of formulation such as temperature or salinity close to the ideal value. Hydrophiliclipophilic deviation (HLD) for ideal value is near to core level for a system, for example, adopting higher temperature to microemulsion. (ii) The phase transition from a near-ideal state through a change in multiple variables, which means that by changing multiple variables of the formulation. For example, employing higher temperature and including a new salt in a microemulsion. (iii) Catastrophic inversion, wherein an inversion of the internal phase occurs at low temperature within the emulsion resulting in the transformation of the internal phase to the external phase. (iv) Phase transition stabilized by the establishment of liquid crystals, where nanodroplets stabilization takes place from a condition close to HLD-0 by liquid crystal formation [6].

\section{Brute force method}

This method involves the adoption of brute forces for breaking down the oil droplets into the nano range. Instruments that have been employed for the preparation of NEs are high-pressure homogenizer, high-speed mixer, small pore membrane, and high-frequency ultrasonic device. NE properties such as its small size, optical transparency, and high kinetic stability rely not only on the make-up of variables in addition to the processing variables such as emulsification time, degree of mixing, energy input, and emulsifying path. High-pressure homogenization and microfluidization methods are adopted at industrial as well as laboratory scale for achieving a very small size of NE by employing high-pressure equipment. Many other methods are also being used for the formulation of NE such as ultrasonication and in situ emulsification.

\section{High-pressure homogenization}

For the formulation of NE high shear force is needed; hence, in this procedure high-pressure homogenizer or piston homogenizer is adopted for the manufacturing of NEs with extremely small particle size (up to $1 \mathrm{~nm}$ ) as shown in Fig. 1. In this method, a mixture is pushed forcefully through an orifice at exorbitant pressure ranging from 500 up to $5000 \mathrm{psi}$. The final product is further exposed to powerful turbulence and hydraulic shear ultimately forming an emulsion with extremely fine particles. This has been demonstrated to be the most promising method for NE formulation but the only limitation accompanying this technique is greater energy utilization and an elevation in temperature of the emulsion during preparation. For getting lesser particle size, there is also a need for more runs of homogenization cycles. Yilmaz et al. prepared phytosphingosine $\mathrm{O} / \mathrm{W}$ NEs using a high-pressure 
homogenization technique and found out that droplet size was lessened after going through eight homogenization cycles and the NE so formed was stable for more than 6 months when stored [24].

\section{Microfluidization}

This technique adopted a device called as microfluidizer that makes use of a high-pressure positive displacement pump (500-40,000 psi) that propels the product out through the interaction chamber made up of stainless steel microchannels on the impaction area which resulted in the formation of very small particles of sub-micron range as shown in
Fig. 2. The mixture is again and again flowed through the microfluidizer until the desired particle size is obtained. The final product is also made to proceed through the filter to divide smaller droplets from larger ones and to attain a homogenous NE. Uluata et al. prepared octadecane $0 / \mathrm{W}$ NEs by utilizing a microfluidizer and saw that on enhancing the number of passes and homogenization pressure; the droplet size became reduced [26]. Goh et al. formulated tocotrienol-rich fraction NEs by two-step homogenization wherein a key coarse emulsion was made by employing a stirrer, which was further underwent processing utilizing a microfluidizer. They announced that the droplet size fell from 120 to

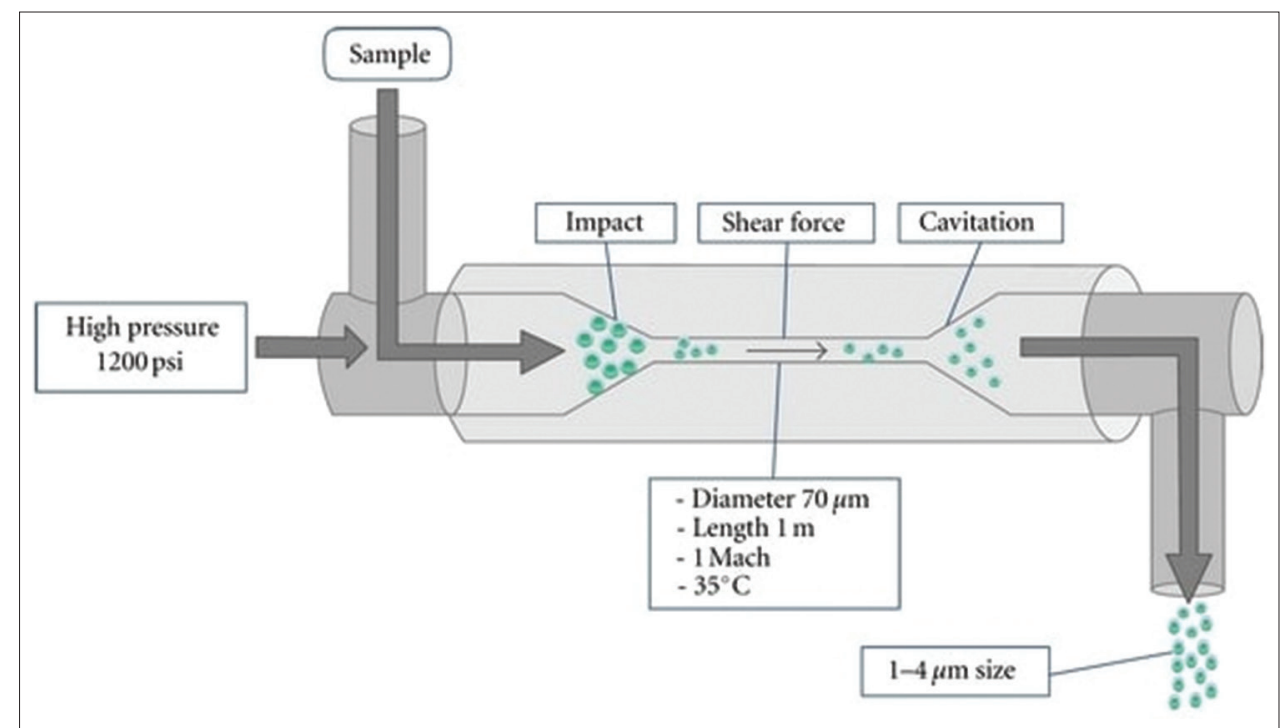

Fig. 1: High-pressure homogenization method. (i) Adapted from Reference [25]. (ii) Copyright obtained under Creative Commons attributed 3.0 (https://creativecommons.org/licenses/by/3.0/)

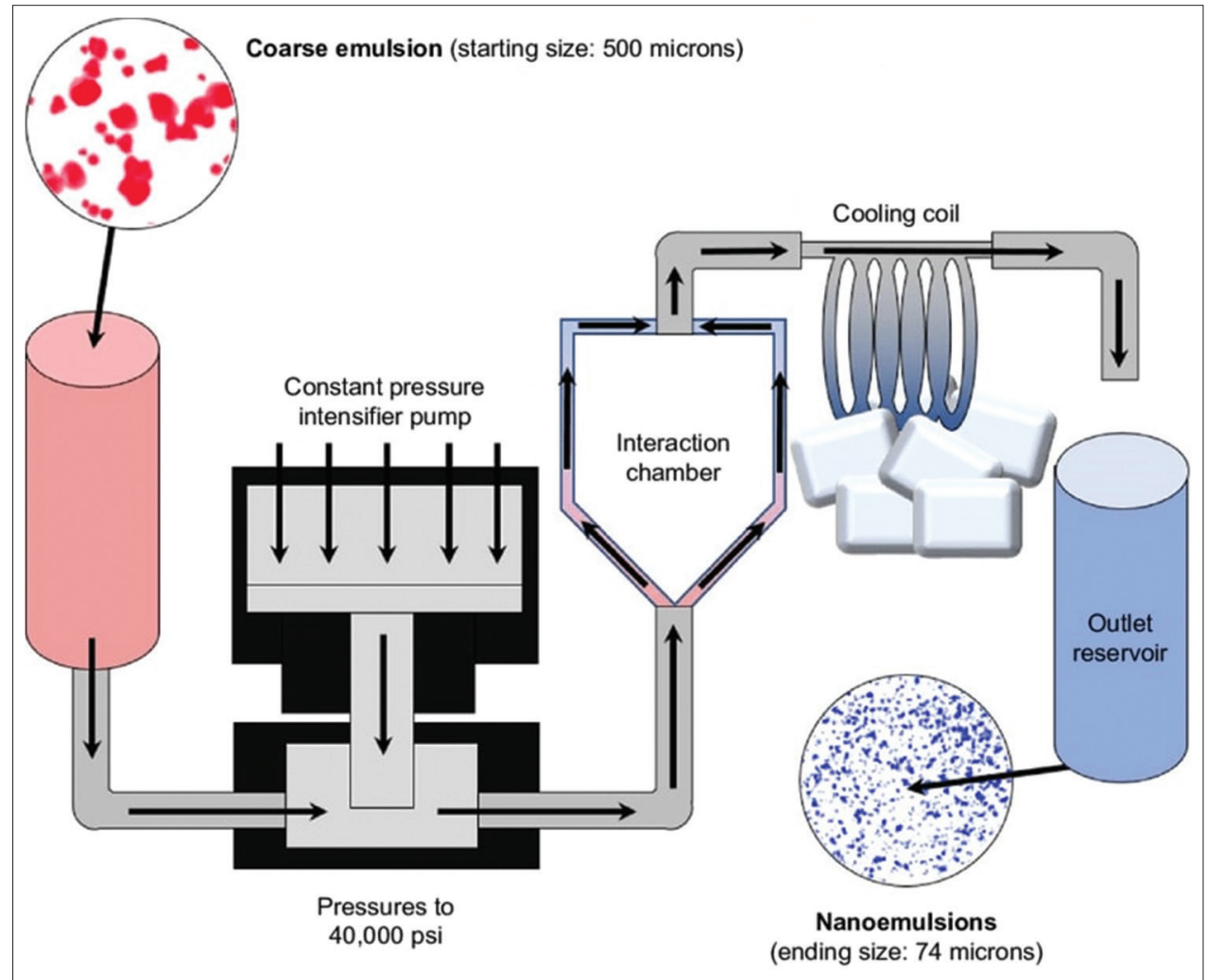

Fig. 2: Microfluidization process. (i) Adapted from reference [28]. (ii) Copyright obtained under Creative Commons Non-Commercial unported 3.0 (https://creativecommons.org/licenses/by-nc/3.0/) 
$65.1 \mathrm{~nm}$ after making the formulation pass through ten homogenization cycles at elevated pressure [27].

\section{Ultrasonication}

In this method, the premixed emulsion is subjected to agitation at an ultrasonic frequency of $20 \mathrm{kHz}$ which shrinks the droplets to nanosize. The emulsion so formed is then made to pass through the high shear area to make droplets with the same size distribution. A water jacket is adopted in this technique to control the temperature. Sonotrodes which are also known as the sonicator probe are constructed of piezoelectric quartz crystals which serve as the energy suppliers during ultrasonic emulsification. On the passage of alternating electric voltage through these sonotrodes, they shrink and expand. Mechanical vibrations are emanated due to this mechanism at the sonicator tip which when touches the liquid results in cavitation, which further leads to the breakdown of vapor cavities formed within the liquid. This method is chiefly used when the droplet size requirement is less than $0.2 \mu$. Shi et al. prepared emodin-loaded NE by adopting ultrasonic emulsification method with a frequency set at $25 \mathrm{kHz}$ and attained an average diameter of 10-30 nm [29].

\section{Spontaneous emulsification}

This method requires the formulation of NE in three steps. The first step involves the preparation of an organic solution, consisting of oil, and lipophilic surfactant dissolved in a water-soluble solvent as well as hydrophilic surfactant after which the $0 / \mathrm{W}$ emulsion is prepared by introducing this organic phase into the aqueous phase under magnetic stirring by means of a syringe. The organic solvent is then abolished in the third stage by evaporation. Sugumar et al. prepared stable eucalyptus oil NEs by employing the spontaneous emulsification method after which the average droplet size was discovered to be in the range of 50-100 $\mathrm{nm}$ [30].

Following are the types of NEs formed depending on the composition

1. O/W NE: Here, the oil droplets are dispersed in the continuous aqueous phase

2. W/O NEs: Here, the water droplets are dispersed in the continuous oil phase

3. Bi-continuous NEs: Here, the microdomains of oil and water are inter-dispersed within the system

In all three categories of NEs, the interface is made stable by a required blend of surfactants and/or co-surfactants [31].

\section{COMPONENTS OF NES}

Three pivotal ingredients are necessary for NE preparation which are 1. Oil

2. Surfactant

3. Co-surfactant.

NEs are basically colloidal systems that consist of three phases namely oil phase, aqueous phase, surfactant, and cosurfactant at acceptable ratios. As contrast to coarse emulsions which are micronized with the aid of outside energy source, NEs are prepared on the basis of low interfacial tension. This is attained by incorporating a cosurfactant, which leads in the voluntary development of a thermodynamically stable NE. The droplet diameter in the dispersed phase is very less, normally below $140 \mathrm{~nm}$ in diameter, which is responsible for transparency in NE, NEs can be employed to administer drugs to the patients through many routes, but the topical application of NEs has shown increasing promise [32]. The three key parameters influencing the transdermal penetration of drugs are the flexibility of the drug in the vehicle, release of the drug from the vehicle, and penetration of the drug into the skin. NEs enhance the transdermal delivery of many drugs over the traditional topical formulations such as emulsions [33,34] as well as gels [35,36]. The flexibility of drugs in NEs is easier [34,36,37] when compared against the NE containing gel former which will elevate its viscosity and further reduce the penetration in the skin [35]. The better transdermal flux from NEs has been demonstrated to be chiefly due to their great solubilization ability for hydrophobic as well as hydrophilic drugs. This creates an enhanced thermodynamic activity toward the skin [36-38]. NEs can influence the penetration of the drug into the skin. In this case, the ingredients of NEs play the role of permeation enhancers. Many compounds employed in NEs have been announced to elevate the transdermal penetration by changing the configuration of the stratum corneum. For example, short-chain alkanols are extensively adopted as permeation enhancers [39-41]. It is recognized that oleic acid, a fatty acid with a single double bond in its chain structure, disturbs the lipid barrier in the stratum corneum by forging different domains which at as a barrier with the continuity of the multilamellar stratum corneum and can bring about vasty permeable alleys in the stratum corneum [4244]. Isopropyl myristate (IPM) is employed as a permeation enhancer in transdermal preparations, but the way it acts is not well understood [45]. Nonionic surfactants are extensively employed in topical preparations which also serve as solubilizing agents but some current conclusions demonstrate that they may also influence the skin barrier function [46]. It is noteworthy to inspect the consequences of these ingredients in the organized NE structures. A quirky venture was taken up to emulsify coconut oil with the aid of polyoxyethylene 2-cetyl ether (Brij 52) as well as isopropanol or ethanol, resulting in the emergence of stable isotropic dispersion thus setting up the stage for adoption of the plant as well as vegetable oil to be employed as oil phase in NE preparations [47].

The surfactants adopted to stabilize such systems can be:

1. Non-ionic

2. Zwitterionic

3. Cationic

4. Anionic surfactants.

A blend of these, specifically ionic, and nonionic, can be extremely useful at elevating the expansion of the NE region. Examples: (i) Non-ionic surfactants are polyoxyethylene such as Brij 35 (C12E35) or sugar esters, namely, sorbitan monooleate (Span 80). (ii) Zwitterionic surfactants list includes phospholipids are an important example and demonstrate outstanding biocompatibility. (iii) Cationic surfactants list includes Lecithin grades from many different sources such as soybean and egg are accessible commercially and comprise of diacylphosphatidylcholine as its key ingredient [48-51]. Quaternary ammonium alkyl salts are one of the exceptional appreciated classes of cationic surfactants, where hexadecyltrimethylammonium bromide (CTAB) and the double-tailed surfactant didodecyldimethylammonium bromide (DDAB) are among the most recognized. (iv) Anionic surfactant examples are sodium bis2- ethyl hexyl sulfosuccinate (AOT) is a double-tailed surfactant that is mainly utilized as a successful stabilizer for w/o microemulsions [52]. Endeavors have been taken to justify surfactant behavior with respect to the hydrophile-lipophile balance (HLB) [53], and the critical packing parameter (CPP) $[54,55]$. Both viewpoints are reasonably real but can serve as a convenient guide towards surfactant selection. The HLB value decides the relative credit of hydrophilic as well as hydrophobic pieces of the surfactant molecule. It is normally recognized surfactants possessing less HLB (3-6) are recommended for the preparation of w/o NEs while surfactants with high HLBs (8-18) are advised for the preparation of o/w NE systems. Ionic surfactants, namely, sodium dodecyl sulfate which carries HLB values higher than 20, often need the existence of a cosurfactant to lessen their functional HLB to a value within the window desired for NE preparation. Conversely, the CPP points to the property of surfactant to make specific aggregates to the configuration of the molecule itself. In nearly all cases, single-chain surfactants when employed singly are not capable to lessen the oil/ water interfacial tension to a point to allow a microemulsion to form, an issue highlighted in many existing microemulsions reviews [56-60]. Medium-chain length alcohols which are traditionally incorporated as cosurfactants have the consequences of additionally lessening the interfacial tension while enhancing the mobility of the interface which elevates the entropy of the system $[57,58]$. Medium-chain length alcohols also enhance the mobility of the hydrocarbon tails as well as also permitting higher permeation of the oil into this region. 
Table 1: Various methods adopted in the preparation of nanoemulsions [7-23]

\begin{tabular}{|c|c|c|c|}
\hline Method & Formulation & Inference & References \\
\hline High-pressure homogenization & Oral nanoemulsion (primaquine) & Better oral bioavailability, $10-200 \mathrm{~nm}$ particle size & [7] \\
\hline $\begin{array}{l}\text { Pseudo ternary phase } \\
\text { diagram+spontaneous } \\
\text { emulsification method }\end{array}$ & Ramipril nanoemulsion & Upgraded bioavailability, droplet size $80.9 \mathrm{~nm}$ & [8] \\
\hline High-pressure homogenization & O/W nanoemulsions & Boosted skin hydration as well as elasticity & [9] \\
\hline Spontaneous emulsification & O/W nanoemulsion (aceclofenac) & $\begin{array}{l}\text { Nanoemulsion with a promising likelihood of } \\
\text { transdermal delivery of aceclofenac }\end{array}$ & {$[10]$} \\
\hline High-pressure homogenization & $\begin{array}{l}\text { Lecithin-based } \\
\text { nanoemulsions (progesterone) }\end{array}$ & $\begin{array}{l}\text { Enhanced permeation rates of progesterone offering } \\
\text { long-term stability }\end{array}$ & [12] \\
\hline High-pressure homogenization & Prednicarbate nanoemulsion & $\begin{array}{l}\text { Enhanced chemical stability of the drug in the } \\
\text { formulation }\end{array}$ & [13] \\
\hline $\begin{array}{l}\text { Phase inversion temperature } \\
\text { method }\end{array}$ & $\begin{array}{l}\text { Acyclovir-loaded multiple } \mathrm{W} / 0 / \mathrm{W} \\
\text { nanoemulsions }\end{array}$ & $\begin{array}{l}\text { Very good physicochemical stability for } 6 \text { months at } \\
\text { RT, mean droplet size of } 100 \mathrm{~nm}\end{array}$ & [14] \\
\hline $\begin{array}{l}\text { Spontaneous nano } \\
\text { emulsification method }\end{array}$ & Clotrimazole nanoemulsion & $\begin{array}{l}\text { Enhanced solubility of clotrimazole, mean globule size } \\
\text { lesser than } 25 \mathrm{~nm}\end{array}$ & [15] \\
\hline $\begin{array}{l}\text { Ultrasonic emulsification } \\
\text { method }\end{array}$ & Basil oil nanoemulsion & $\begin{array}{l}\text { Nanoemulsions with a droplet size of } 29.6 \mathrm{~nm} \text {, used as } \\
\text { food preservatives }\end{array}$ & {$[16]$} \\
\hline High-pressure homogenizer & $\begin{array}{l}\text { Dimethyl silicone dry } \\
\text { nanoemulsion inhalation }\end{array}$ & Useful in acute lung injury, the particle size of $19.8 \mathrm{~nm}$ & [17] \\
\hline Microfluidization method & $\begin{array}{l}\text { Pitavastatin-containing } \\
\text { nanoemulsions }\end{array}$ & Boosted permeation & [18] \\
\hline $\begin{array}{l}\text { High-pressure } \\
\text { homogenization+ultrasound }\end{array}$ & Nanoemulsion & $\begin{array}{l}\text { Less energy required for emulsification, fewer particle } \\
\text { dimensions, and greater stability }\end{array}$ & [19] \\
\hline Sonication method & $\begin{array}{l}\text { Saponin-stabilized } \\
\text { quercetin-loaded o/w } \\
\text { nanoemulsion }\end{array}$ & $\begin{array}{l}\text { No instability is seen for } 45 \text { days at RT, mean particle } \\
\text { size of } 52 \pm 10 \mathrm{~nm}\end{array}$ & {$[20]$} \\
\hline High-pressure homogenization & Paclitaxel-baicalein nanoemulsion & Scheme to tame multidrug resistance & {$[21]$} \\
\hline Nanoemulsion templating & PLGA nanoparticles & Imaging agents for biomedical applications & [22] \\
\hline $\begin{array}{l}\text { Spontaneous emulsification } \\
\text { method }\end{array}$ & $\begin{array}{l}\text { Chitosan films with } \\
\text { cinnamaldehyde nanoemulsions }\end{array}$ & Offer Adequate UV barrier properties & [23] \\
\hline
\end{tabular}

Table 2: NEs utilized as adjuvants [81-87]

\begin{tabular}{|c|c|c|c|}
\hline $\begin{array}{l}\text { Adjuvant } \\
\text { utilized }\end{array}$ & Ingredients & Uses & References \\
\hline MF59® & $\begin{array}{l}\text { O/W Squalene } \\
\text { containing emulsion }\end{array}$ & Influenza & {$[81,82]$} \\
\hline AS03 & $\begin{array}{l}\text { SB62 adjuvant and } \\
\text { twice diluted form of } \\
\text { O/W squalene }\end{array}$ & $\begin{array}{l}\text { H5N1 and } \\
\text { H1N1 }\end{array}$ & [83] \\
\hline AS02 & $\begin{array}{l}\text { Immune-stimulatory } \\
\text { agents, for example, } \\
\text { MPL and triterpenoid } \\
\text { saponin molecules }\end{array}$ & $\begin{array}{l}\text { Malaria, } \\
\text { HIV, and } \\
\text { tuberculosis }\end{array}$ & [84] \\
\hline MPL®SE & $\begin{array}{l}\text { Blend of } \\
\text { monophosphoryl lipid } \\
\text { and a stable squalene } \\
\text { emulsion }\end{array}$ & Leishmaniasis & [85] \\
\hline AF03 & $\begin{array}{l}\text { Thermoreversible } \\
\text { O/W nanoemulsions }\end{array}$ & H1N1 influenza & [86] \\
\hline DETOX® & $\begin{array}{l}\text { Composed of } \\
\text { bacterial cell wall and } \\
\text { monophosphoryl lipid } \\
\text { A (MPL) dissolved in } \\
\text { squalane and Tween } 8\end{array}$ & Melanoma & [87] \\
\hline
\end{tabular}

\section{APPLICATIONS}

Ophthalmic and pulmonary delivery

For the therapy of eye diseases, drugs are mainly administered topically in the form of o/w NEs which have been studied for ocular delivery, to solubilize poorly soluble drugs, in an effort to enhance absorption, and to achieve prolonged release effect. The NEs comprising pilocarpine were prepared using lecithin, propylene glycol, and PEG 200 as cosurfactant and IPM acting as the oil phase. The preparations were found to be less viscous with a refractive index acceptable toward ophthalmologic applications [31]. Morsi et al. formulated a new NE of acetazolamide where the particle size ranged from $23 \mathrm{~nm}$ to $90 \mathrm{~nm}$ [61].

\section{Cosmetics}

The advantage of using NEs in cosmetics is the tiny droplet size and omission of creaming as well as flocculation, which pave the way for the uptake by antigen-presenting cells and results into a pure product formulation [62]. Ribeiro et al. [63] prepared O/WNEs containing Opuntia ficus-indica (L.) Mill hydroglycolic extract as well as xanthan gum with droplet sizes ranging from 92.2 to $233.6 \mathrm{~nm}$. The 0/WNEs comprising $1 \%$ of 0 . ficus-indica (L.) Mill extract was absence from any stability issues for 60 days. Furthermore, this formulation enhanced the water content of stratum corneum, demonstrating its moisturizing ability to be a superior product for cosmetics. NEs were prepared by Pengon et al. [64] by utilizing coconut oil NEs and diversed amounts of surfactants including polyethylene glycol octyl phenyl ether (PGO) as well as polyethylene glycol hydrogenated castor oil (PHC). The droplet size of NEs comprising 5\% (w/w) PHC was found to be $0.162 \mathrm{~m}$. An even lesser size of coconut oil NEs could be obtained by elevating the concentration of PHC. NE formulations were formulated from the hydroalcoholic extracts of Vellozia squamata leaves as well as stems with inflated antioxidant activity by utilizing the phase inversion method. Stable formulations were achieved from both extracts from leaves as well as stems. Antioxidants are popular as anti-aging agents and therefore are acceptable for cosmetics formulation [65]. NEs have also been utilized as a vehicle for controlled delivery and as an effective transport vehicle in cosmetics. NEs will lessen trans-epidermal water loss. The Kemira nano gel- made up of NEs serving as a carrier is a patented formulation intended for cosmetic uses; which will enhance skin cell production as well as the penetration of API to give a good skin sensation [66]. Thananya et al. formulated a mixture of essential oils in 
NEs dosage form for an anti-tyrosinase activity where the droplet size was found to be ranging from $29 \mathrm{~nm}$ to $35 \mathrm{~nm}$ and showed well in vitro anti-tyrosinase activity plus these formulations were also found to be stable even after 3 months of storage [67].

\section{Asthma}

Yasser et al. formulated NE of montelukast sodium where the mean droplet size ranged from about 65 to $85 \mathrm{~nm}$ and drug release from this formulation was found to be $93 \%$ after a period of 30 min [68].

\section{Anti-inflammatory}

The blending of oils and emulsifiers improved the absorption of two phytochemicals that are now utilized in treating two major chronic inflammatory diseases which are periodontitis [68] and bowel disease (Crohn's disease and ulcerative colitis) [69]. Periodontitis is a longterm inflammatory disease that attacks the supporting structures of the teeth with many factors such as microbial, genetic, environmental, and host factor play a role in the beginning of that condition. A state of long-term inflammation will take place with the release of oxygenfree radicals by inflammatory cells (polymorphonuclear lymphocytes). Enzymes and toxic by-products given out by the periodontal pathogenic microflora further enhance this destructive activity by breaking down affected cell membranes and extracellular matrices to get nutrients very important for their suistainence [70]. In Crohn's disease, the entire intestinal wall may be attacked by inflammation and is normally transmural and non-continuous, meanwhile in ulcerative colitis, it is many a times continuous, primarily affecting only on the mucosal lining of the colon and rectum [71]. Multiple reasons might reside behind the origin of the diseases including complicated interplays between oxidative stress, immunoregulation, altered inflammatory mediator levels, microbial pathogens, as well as genetic reasons [72]. Phytochemicals have been announced by fresh investigations to be handful in recovering both diseases. Quercetin, a class of bioflavonoids that have treated periodontitis [73], and diterpenoid extracted from Andrographis paniculata to remedy bowel diseases [74], have shown possible antimicrobial activity, lessening inflammatory markers, as well as demonstrating anti-inflammatory, antioxidative [75], as well as anticancer activities [76]. But, both ingredients have less aqueous solubility $(0.07 \mathrm{mg} / \mathrm{mL}$ in water), which has resulted in lesser bioavailability, and due to rapid and large scale metabolism, they have lesser oral absorption. Absorption of both phytochemicals can be enhanced with the blending of oils and emulsifiers serving as carriers for the active components [77]. Hence, for lipophilic drug loading, NEs could be a proper drug delivery vehicle. The speed of absorption is good and changes in in absorption rates is bypassed completely and NEs also make way in solubilizing lipophilic drug, enhancing bioavailability, and authorize rapid and systematic puncturing of the drug molecule. In situ nanoemulgels could be made when NEs are added into the polymer solution, which pertains sustained as well as controlled drug delivery and pave way for administration, thus patient compliance with drug will be further enhanced [69].

\section{Vaccine delivery}

NEs being serving as a vaccine carrier are busily being investigated. The present affective and well-organized procedure is to administer an inactivated organism to a mucosal surface so that an immune response will be activated by the body. Studies have demonstrated that genital mucosa immunity can be generated with vaccines that are delivered into the nasal mucosa as required [78]. Proteins were administered to the mucosal surface by utilizing NEs to act as an adjuvant and govern the absorption of antigen-presenting cells. The antigen can be trapped in the nanocarrier by many mechanisms including physical adsorption, encapsulation, encapsulation with coating, encapsulation with targeting, chemical linking, and conjugation along with a targeting mechanism. The physical adsorption of the antigen onto a nanocarrier can be attained either by a charge or hydrophobic interaction, which demonstrates a weak interaction that leads to the braking of the antigen and nanocarrier bond in the body thus releasing the antigen. As far as the encapsulation is concerned, antigens are blended with nanocarrier precursors during their synthesis, which leads in the entrapment of antigen into the nanocarrier [79]. The very first application that is currently getting clinical trials is the nanocarrier for influenza and HIV protein. Furthermore, a recombinant HIV gp 120 antigen mix in NEs has been injected into mice as well as guinea pigs through intranasal immunization that show robust serumanti-gp 120 IgG levels [80]. Another noteworthy example is the pandemic flu vaccine AS03, which has been accepted as a constituent of Prepandrix® [81]

\section{CONCLUSION}

As described NEs provide a platform on which drugs that are less watersoluble can be delivered successfully. They utilize oils and surfactants to solubilize the drug in the aqueous phase which then serves as a carrier. The various methods of preparation of NEs along with their composition followed by their subsequent applications were discussed in this review. NEs are a new frontier in novel drug delivery systems and will continue to progress ahead with new advancements in the future.

\section{ACKNOWLEDGMENT}

The authors are thankful toward the staff of H.K. College of Pharmacy for guiding toward the preparation of this manuscript.

\section{AUTHORS CONTRIBUTION}

Manuscript framing and the concept has been presented by Khan Mohammad Hamid. Literature search and preparation have been done by Gaurang Sawant. Reviewing and editing have been done by Mohammad Wais.

\section{CONFLICT OF INTERESTS}

The authors have declared no conflicts of interest.

\section{AUTHORS FUNDING}

As this is a review article, no funding was provided for this study.

\section{REFERENCES}

1. Ahuja A, Ali J, Baboota S, Faisal M, Shakeell F, Shafiq S. Stability evaluation of celecoxib nanoemulsion containing Tween 80 . Thai $\mathrm{J}$ Pharm Sci 2008;32:4-9.

2. Nigade PM, Patil SL, Tiwari SS. Self-emulsifying drug delivery system (SEDDS): A Review. Int J Pharm Biol Sci 2012;2:42-52.

3. Kumar S. Role of nano-emulsion in pharmaceutical sciences-a review. Asian J Res Pharm Sci Biotech 2014;2:1-15.

4. Bhosale RR, Osmani RA, Ghodake PP, Shaikh SM, Chavan SR. Nanoemulsion: A review on novel profusion in advanced drug delivery. Indian J Pharm Biol Res 2014;2:122-7.

5. Jaiswal M, Dudhe R, Sharma PK. Nanoemulsion: An advanced mode of drug delivery system. 3 Biotech 2015;5:123-7.

6. Gurpreet K, Singh SK. Review of nanoemulsion formulation and characterization techniques. Indian J Pharm Sci 2018;80:781-9.

7. Singh KK, Vingkar SK. Formulation, antimalarial activity and biodistribution of oral lipid nanoemulsion of primaquine. Int $\mathrm{J}$ Pharm 2008;347:136-43.

8. Shafiq S, Shakeel F, Talegaonkar S, Ahmad FJ, Khar RK, Ali M. Development and bioavailability assessment of ramipril nanoemulsion formulation. Eur J Pharm Biopharm 2007;66:227-43.

9. Yilmaz E, Borchert HH. Effect of lipid-containing, positively charged nanoemulsions on skin hydration, elasticity and erythema--an in vivo study. Int J Pharm 2006;307:232-8.

10. Shakeel F, Baboota S, Ahuja A, Ali J, Aqil M, Shafiq S. Nanoemulsions as vehicles for transdermal delivery of aceclofenac. AAPS PharmSciTech 2007;8:E104.

11. Shakeel F, Baboota S, Ahuja A, Ali J, Aqil M, Shafiq S. Accelerated stability testing of celecoxib nanoemulsion containing cremophor-EL. Afr J Pharm Pharmacol 2008;2:179-83.

12. Klang V, Matsko N, Zimmermann AM, Vojnikovic E, Valenta C. Enhancement of stability and skin permeation by sucrose stearate and cyclodextrins in progesterone nanoemulsions. Int $\mathrm{J}$ Pharm 2010;393:152-60.

13. Baspinar Y, Keck CM, Borchert HH. Development of a positively 
charged prednicarbate nanoemulsion. Int J Pharm 2010;383:201-8.

14. Schwarz JC, Klang V, Karall S, Mahrhauser D, Resch GP, Valenta C. Optimisation of multiple $\mathrm{W} / \mathrm{O} / \mathrm{W}$ nanoemulsions for dermal delivery of aciclovir. Int J Pharm 2012;435:69-75.

15. Borhade V, Pathak S, Sharma S, Patravale V. Clotrimazole nanoemulsion for malaria chemotherapy. Part I: preformulation studies, formulation design and physicochemical evaluation. Int J Pharm 2012;431:138-48.

16. Ghosh V, Mukherjee A, Chandrasekaran N. Ultrasonic emulsification of food-grade nanoemulsion formulation and evaluation of its bactericidal activity. Ultrason Sonochem 2013;20:338-44

17. Zhu L, Li M, Dong J, Jin Y. Dimethyl silicone dry nanoemulsion inhalations: Formulation study and anti-acute lung injury effect. Int J Pharm 2015;491:292-8.

18. Başpınar Y, Gündoğdu E, Köksal C, Karasulu E. Pitavastatin-containing nanoemulsions: Preparation, characterization and in vitro cytotoxicity. J Drug Deliv Sci Technol 2015;29:117-24

19. Calligaris S, Plazzotta S, Bot F, Grasselli S, Malchiodi A, Anese M. Nanoemulsion preparation by combining high pressure homogenization and high power ultrasound at low energy densities. Food Res Int 2016; 83:25-30

20. Kaur K, Kumar R, Mehta SK. Formulation of saponin stabilized nanoemulsion by ultrasonic method and its role to protect the degradation of quercitin from UV light. Ultrason Sonochem 2016;31:29-38

21. Meng L, Xia X, Yang Y, Ye J, Dong W, Ma P, et al. Co-encapsulation of paclitaxel and baicalein in nanoemulsions to overcome multidrug resistance via oxidative stress augmentation and P-glycoprotein inhibition. Int J Pharm 2016;513:8-16.

22. Fornaguera C, Feiner-Gracia N, Calderó G, García-Celma MJ, Solans C. PLGA nanoparticles from nano-emulsion templating as imaging agents: Versatile technology to obtain nanoparticles loaded with fluorescent dyes. Colloids Surf B Biointerfaces 2016;147:201-9.

23. Chen H, Hu X, Chen E, Wu S, McClements DJ, Liu S, et al. Preparation, characterization, and properties of chitosan films with cinnamaldehyde nanoemulsions. Food Hydrocoll 2016;61:662-71.

24. Yilmaz E, Borchert HH. Design of a phytosphingosine-containing, positively-charged nanoemulsion as a colloidal carrier system for dermal application of ceramides. Eur J Pharm Biopharm 2005;60:91-8.

25. Cho SC, Choi WY, Oh SH, Lee CG, Seo YC, Kim JS, et al. Enhancement of lipid extraction from marine microalga, Scenedesmus associated with high-pressure homogenization process. J Biomed Biotechnol 2012;2012:359432.

26. Uluata S, Decker EA, McClements DJ. Optimization of nanoemulsion fabrication using microfluidization: role of surfactant concentration on formation and stability. Food Biophys 2016; 11:52-9.

27. Goh PS, Ng MH, Choo YM, Amru NB, Chuah CH. Production of nanoemulsions from palm-based tocotrienol rich fraction by microfluidization. Molecules 2015;20:19936-46.

28. Ganesan P, Karthivashan G, Park SY, Kim J, Choi DK. Microfluidization trends in the development of nanodelivery systems and applications in chronic disease treatments. Int J Nanomedicine 2018;13:6109-21.

29. Shi Y, Li H, Li J, Zhi D, Zhang X, Liu H, et al. Development, optimization and evaluation of emodin loaded nanoemulsion prepared by ultrasonic emulsification. J Drug Deliv Sci Technol 2015;27:46-55.

30. Sugumar S, Mukherjee A, Chandrasekaran N. Nanoemulsion formation and characterization by spontaneous emulsification: Investigation of its antibacterial effects on Listeria monocytogenes. Asian J Pharm 2015;9:23-8

31. Shinoda K, Lindman B. Organised surfactant systems: Microemulsions. Langmuir 1987;3:135-49.

32. Tenjarla S. Microemulsions: An overview and pharmaceutical applications. Crit Rev Ther Drug Carrier Syst 1999;16:461-521 .

33. Ktistis G, Niopas IA study on the in-vitro percutaneous absorption of propranolol from disperse systems. J Pharm Pharmacol 1998;50:413-8.

34. Kreilgaard M, Pedersen EJ, Jaroszewski JW. NMR characterization and transdermal drug delivery potential of microemulsion systems. J Control Release 2000;69:421-33

35. Gasco MR, Gallarate M, Pattarino F. In-vitro permeation of azelaic acid from viscosized microemulsion. Int J Pharm 1991;69:193-6.

36. Kriwet K, Müller-Goymann CC. Diclofenac release from phospholipid drug systems and permeation through excised human stratum corneum. Int J Pharm 1995;125:231-42.

37. Trotta M. Influence of phase transformation on indomethacin release from microemulsions. J Control Release 1999;60:399-405.

38. Alvarez-Figueroa MJ, Blanco-Méndez J. Transdermal delivery of methotrexate: Iontophoretic delivery from hydrogels and passive delivery from microemulsions. Int J Pharm 2001;215:57-65.

39. Pershing LK, Lambert LD, Knutson K. Mechanism of ethanol-enhanced estradiol permeation across human skin in vivo. Pharm Res 1990;7:170-5.

40. Liu P, Kurihara-Bergstrom T, Good WR. Cotransport of estradiol and ethanol through human skin in vitro: Understanding the permeant/ enhancer flux relationship. Pharm Res 1991;8:938-44.

41. Kim YH, Ghanem AH, Mahmoud H, Higuchi WI. Short chain alkanols as transport enhancers for lipophilic and polar/ionic permeants in hairless mouse skin: mechanism (s) of action. Int J Pharm 1992;80:17-31.

42. Pershing LK, Parry GE, Lambert LD. Disparity of in vitro and in vivo oleic acid-enhanced $\beta$-estradiol percutaneous absorption across human skin. Pharm Res 1993;10:1745-50.

43. Tanojo H, Boelsma E, Junginger HE, Ponec M, Boddé HE. In vivo human skin permeability enhancement by oleic acid: A laser Doppler velocimetry study. J Control Release 1999;58:97-104

44. Hadgraft J. Skin, the final frontier. Int J Pharm 2001;224:1-8.

45. Goldberg-Cettina M, Liu P, Nightingale J, Kurihara-Bergstrom T. Enhanced transdermal delivery of estradiol in vitro using binary vehicles of isopropyl myristate and short-chain alkanols. Int J Pharm 1995;114:237-45.

46. Fang JY, Yu SY, Wu PC, Huang YB, Tsai YH. In vitro skin permeation of estradiol from various proniosome formulations. Int $\mathrm{J}$ Pharm 2001;215:91-9.

47. Acharya A, Moulik SP, Sanyal SK, Mishra BK, Puri PM. Physicochemical investigations of microemulsification of coconut oil and water using polyoxyethylene 2-cetyl ether (Brij 52) and isopropanol or ethanol. J Colloid Interface Sci 2002;245:163-70.

48. Attwood D, Mallon C, Taylor CJ. Phase studies on oil-in-water phospholipid microemulsions. Int J Pharm 1992;84:R5-8.

49. Aboofazeli R, Lawrence CB, Wicks SR, Lawrence MJ. Investigations into the formation and characterization of phospholipid microemulsions. III. Pseudo-ternary phase diagrams of systems containing waterlecithin-isopropyl myristate and either an alkanoic acid, amine, alkanediol, polyethylene glycol alkyl ether or alcohol as cosurfactant. Int J Pharm 1994;111:63-72.

50. Aboofazeli R, Lawrence MJ. Investigations into the formation and characterization of phospholipid microemulsions: I Pseudo-ternary phase diagrams of systems containing water lecithin-alcohol-isopropyl myristate. Int J Pharm 1993;93:161-75.

51. Shinoda K, Araki M, Sadaghiani A, Khan A, Lindman B. Lecithinbased microemulsions: Phase behavior and microstructure. J Phys Chem 1991;95:989-93

52. D’Angelo M, Fioretto D, Onori G, Palmieri L, Santucci A. Dynamics of water-containing sodium bis(2-ethylhexyl)sulfosuccinate (AOT) reverse micelles: A high-frequency dielectric study. Phys Rev E Stat Phys Plasmas Fluids Relat Interdiscip Topics 1996;54:993-6.

53. Carlfors J, Blute I, Schmidt V. Lidocaine in microemulsion-a dermal delivery system. J Dispers Sci Technol 1991;12:467-82.

54. Israelachvili JN, Mitchell DJ, Ninham BW. Theory of self-assembly of hydrocarbon amphiphiles into micelles and bilayers. J Chem Soc Faraday Trans 1976;72:1525-68.

55. Mitchell DJ, Ninham BW. Micelles, vesicles and microemulsions. J Chem Soc Faraday Trans 1981;77:601-29.

56. Bhargava HN, Narurkar A, Lieb LM. Using microemulsions for drug delivery. Pharm Technol 198; 11:46-54.

57. Kreuter J. Colloidal Drug Delivery Systems. Boca Raton, Florida: CRC Press; 2014.

58. Eccleston J, Swarbrick JC. Encyclopedia of Pharmaceutical Technology. Vol. 9. New York: Marcel Dekker; 1994. p. 375-421.

59. Lawrence MJ. Surfactant systems: Microemulsions and vesicles as vehicles for drug delivery. Eur J Drug Metab Pharmacokinet 1994;19:257-69.

60. Lawrence MJ. Microemulsions as drug delivery vehicles. Curr Opin Colloid Interface Sci 1996;1:826-32.

61. Morsi NM, Mohamed MI, Refai H, El Sorogy HM. Nanoemulsion as a novel ophthalmic delivery system for acetazolamide. Int J Pharm Pharm Sci 2014;6:227-36.

62. Chellapa P, Ariffin FD, Eid AM, Almahgoubi AA, Mohamed AT, Issa YS, et al. Nanoemulsion for cosmetic application. Eur J Biomed Pharm Sci 2016;3:8-11.

63. Ribeiro RC, Barreto SM, Ostrosky EA, da Rocha-Filho PA, Veríssimo LM, Ferrari M. Production and characterization of cosmetic nanoemulsions containing Opuntia ficus-indica (L.) mill extract as moisturizing agent. Molecules 2015;20:2492-509.

64. Pengon S, Chinatangkul N, Limmatvapirat C, Limmatvapirat S. The effect of surfactant on the physical properties of coconut oil nanoemulsions. Asian J Pharm Sci 2018;13:409-14

65. Quintão FJ, Tavares RS, Vieira-Filho SA, Souza GH, Santos OD. Hydroalcoholic extracts of Vellozia squamata: Study of its 
nanoemulsions for pharmaceutical or cosmetic applications. Rev Bras Farmacogn 2013;23:101-7.

66. Guglielmini G. Nanostructured novel carrier for topical application. Clin Dermatol 2008;26:341-6.

67. Nantarat TH, Chansakaow SU, Leelapornpisid PI. Optimization, characterization and stability of essential oils blend loaded nanoemulsions by PIC technique for anti-tyrosinase activity. Int $\mathrm{J}$ Pharm Pharm Sci 2015;7:308-12.

68. Almajidi YQ, Zainab HM, Maraie NK. Preparation and in vitro evaluation of montelukast sodium oral nanoemulsion. Int J Appl Pharm 2018;10:49-53.

69. Aithal GC, Nayak UY, Mehta C, Narayan R, Gopalkrishna P, Pandiyan $\mathrm{S}$, et al. Localized in situ nanoemulgel drug delivery system of quercetin for periodontitis: Development and computational simulations. Molecules 2018;23:1363.

70. Yen CC, Chen YC, Wu MT, Wang CC, Wu YT. Nanoemulsion as a strategy for improving the oral bioavailability and anti-inflammatory activity of andrographolide. Int J Nanomedicine 2018;13:669-80.

71. Javed S, Kohli K. Local delivery of minocycline hydrochloride: A therapeutic paradigm in periodontal diseases. Curr Drug Deliv 2010;7:398-406

72. Podolsky DK. Inflammatory bowel disease. N Eng J Med 1991;325:928-37.

73. Colitis-Pathophysiology U. Inflammatory bowel disease part I: Ulcerative colitis-pathophysiology and conventional and alternative treatment options. Altern Med Rev 2003;8:247-83.

74. Geoghegan F, Wong RW, Rabie AB. Inhibitory effect of quercetin on periodontal pathogens in vitro. Phytother Res 2010;24:817-20.

75. Madav S, Tripathi HC, Mishra SK. Analgesic, antipyretic and antiulcerogenic effects of andrographolide. Indian J Pharm Sci 1995;57:121.

76. Shen T, Yang WS, Yi YS, Sung GH, Rhee MH, Poo H, et al. AP-1/ IRF-3 targeted anti-inflammatory activity of andrographolide isolated from Andrographis paniculata. Evid Based Complement Alternat Med
2013;2013:210736.

77. Wang J, Tan XF, Nguyen VS, Yang P,Zhou J, Gao M, etal.Aquantitative chemical proteomics approach to profile the specific cellular targets of andrographolide, a promising anticancer agent that suppresses tumor metastasis. Mol Cell Proteomics 2014;13:876-86.

78. Berkowitz AC, Goddard DM. Novel drug delivery systems: future directions. J Neurosci Nurs 2009;41:115-20.

79. Zhao L, Seth A, Wibowo N, Zhao CX, Mitter N, Yu C, et al. Nanoparticle vaccines. Vaccine 2014;32:327-37.

80. Akhter S, Jain GK, Ahmad FJ, Khar RK, Jain N, Khan ZI, Talegaonkar S. Investigation of nanoemulsion system for transdermal delivery of domperidone: Ex-vivo and in vivo studies. Current Nanosci 2008; $4: 381-90$

81. Reed SG, Bertholet S, Coler RN, Friede M. New horizons in adjuvants for vaccine development. Trends Immunol 2009;30:23-32.

82. Pellegrini M, Nicolay U, Lindert K, Groth N, Della Cioppa G. MF59adjuvanted versus non-adjuvanted influenza vaccines: Integrated analysis from a large safety database. Vaccine 2009;27:6959-65.

83. Mosca F, Tritto E, Muzzi A, Monaci E, Bagnoli F, Iavarone C, et al. Molecular and cellular signatures of human vaccine adjuvants. Proc Natl Acad Sci U S A 2008;105:10501-6.

84. Garçon N, Vaughn DW, Didierlaurent AM. Development and evaluation of $\mathrm{AS03}$, an adjuvant system containing $\alpha$-tocopherol and squalene in an oil-in-water emulsion. Expert Rev Vaccines 2012;11:349-66.

85. Garçon N, Di Pasquale A. From discovery to licensure, the adjuvant system story. Hum Vaccin Immunother 2017;13:19-33.

86. Fox CB, Anderson RC, Dutill TS, Goto Y, Reed SG, Vedvick TS. Monitoring the effects of component structure and source on formulation stability and adjuvant activity of oil-in-water emulsions. Colloids Surf B Biointerfaces 2008;65:98-105.

87. Klucker MF, Dalençon F, Probeck P, Haensler J. AF03, an alternative squalene emulsion-based vaccine adjuvant prepared by a phase inversion temperature method. J Pharm Sci 2012;101:4490-500. 